Original Article

\title{
A Study On Health-Related Quality of Life Among The Stroke Patients In A Tertiary Care Hospital, Mangalore
}

\author{
G Shiny Chrism Queen Nesan ${ }^{1}$, Rashmi Kundapur ${ }^{2}$ \\ ${ }^{1}$ Postgraduate, ${ }^{2}$ Professor, Department of Community Medicine, K.S. Hegde Medical Academy, NITTE (DU), Mangalore. \\ Corresponding Author: G Shiny Chrism Queen Nesan, Postgraduate, Department of Community Medicine, KSHEMA, NITTE (DU), \\ Deralakatte, Mangalore. Mobile :+919500101858, E-mail : shinynesan75@gmail.com
}

$\begin{array}{ll}\text { Received } & : 16.02 .2018 \\ \text { Review Completed } & : 12.10 .2018 \\ \text { Accepted } & : 25.10 .2018\end{array}$

Keywords : Stroke, Quality of life, physical and psychological domains

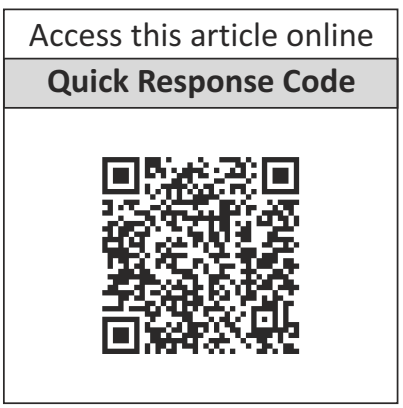

\author{
Abstract : \\ Introduction : Stroke is a leading cause of death and acquired human disability in India. One \\ dimension that is rarely measured, is health-related quality of life (HRQOL) which aims to assess \\ the impact of disease from the perspective of the patient.
}

Objectives : To study the health-related quality of life among stroke patients within 3 months of stroke.

Materials \& Methods : A hospital based study conducted on 20 stroke patients from the registry. The patients with fresh stroke attack and those who were attending the follow up within the first 3 months of the attack were enrolled in the study. Basic demographic data and the data of stroke outcomes were taken. HRQOL was evaluated using the Indian version of the Medical Outcomes Study 36 item Short-Form Health Survey (SF-36). Frequency and percentages were calculated.

Results: It was seen that majority (55\%) of patients expressed a fair physical domain post stroke. About $40 \%$ were of opinion that their physical domain was poor and the rest said that it was good (5\%). Assessing the psychological domain, majority of the patients said it was poor. Of the 20 patients, 15 (75\%) of them were scaled to have poor social domain and the rest $(25 \%)$ said it was fair. About half (50\%) of the patients showed that they had poor environmental domain. About $15 \%$ of them said that it was good. Majority $(60 \%)$ of the patients had poor general health status.

\section{Introduction}

Stroke remains to be one of the major chronic illnesses world-wide, that health-care organizations will need to address for the next several decades as it can affect virtually all human functions ${ }^{(1)}$, and unlike other disabling conditions, the onset of stroke is sudden, leaving the individual and the family ill-prepared to deal with its sequel ${ }^{(1)}$.

Cerebrovascular disease is the most prevalent neurological disorder in terms of both morbidity and mortality. The term cerebrovascular disease denotes any abnormality of the brain caused by a pathological process of blood vessels. "Stroke" is the clinical designation that applies to all these conditions, particularly when the symptoms begin acutely ${ }^{(2,3)}$. In India, Stroke is a leading cause of death and acquired human disability ${ }^{(4)}$ A review of stroke outcome measures in
174 acute stroke trials showed that death was recorded in $76 \%$, impairment in $76 \%$, disability in $42 \%$ and handicap in only $2 \%{ }^{(5)}$

One dimension that is rarely measured is health-related quality of life (HRQOL) which aims to assess the impact of disease from the perspective of the patient ${ }^{(6)}$. If, with any given intervention, a clinical benefit has been obtained as demonstrated in terms of improved neurological function, an evaluation of the effects on patients' daily functioning, subjective health, and well-being is still highly relevant.

Knowledge of factors associated with HRQOL after stroke would provide valuable information about strategies that professionals and providers of stroke care can address to improve HRQOL for stroke patients. Long term stroke studies have reported that depression, disability, and poor 
social network ${ }^{(7)}$ are associated with poor HRQOL. About $80 \%$ of stroke patients return home after the acute hospitalization and at least one-half of them require permanent or temporary help from other people in the home setting. Caring these patients is burdensome and may influence several objective and subjective aspects of the caregiver's life ${ }^{(8)}$. This study would try to determine what quality of life would be of patients with stroke, its impact on the disease itself and tell us the burden the caregivers face as health is majorly spent out of pocket expenditure in India.

Aims \& Objectives : To study the health-related quality of life among stroke patients within 3 months ofstroke.

\section{Materials \& Method}

A hospital based study repeated cross-sectional study with continuation of Stroke Registry (INSPIRE) which is running in the Institution, a large multi-centre prospective study to know HRQOL (Health related quality of life) and to determine the aetiology, clinical practice and outcomes of stroke. For this study, we considered 20 patients from the registry to know the quality of life of those patients in 3 months' period. Universal sampling technique was adopted to select the study participants which was estimated to be 20 in 3 months. The patients with fresh stroke attack and those who were attending the follow up within the first 3 months of the attack were enrolled into the study. The study was conducted for 2 months.

Basic demographic data and the data of stroke outcomes were taken. HRQOL was evaluated using the Indian version of the Medical Outcomes Study 36 item Short-Form Health Survey (SF-36). The HRQOL assessment was done by asking the subjects themselves, thus excluding those who were too confused or dysphasic to undergo these assessments themselves. Eight domains of health status were assessed: Physical Functioning-PF; Role Physical-RP; Bodily Pain-BP; General Health-GH; Vitality-VT; Social Functioning-SF; Role Emotional-RE; and Mental Health-MH. Each domain was scored. These domains were then computed to produce two summary scales representing physical and mental health. Domains for physical health summary scale
(PHSS) include PF, RP, BP and GH. Mental health summary scale (MHSS) includes VT, SF, RE and MH. SF36 scale has reliably been previously used to evaluate HRQOL long-term after stroke and in all age groups. Thus, patients admitted as fresh cases of stroke and patients attending follow up within the first 3 months of the attack were included and severely affected stroke survivors who need a proxy to complete, patients with aphasia and patients not willing to give consent were excluded from the study.

This study had obtained the ethical clearance approval from the institutional ethical committee of $\mathrm{K} S$ Hegde Medical Academy, Mangalore, Karnataka. Written informed consent was obtained from all study participants before eliciting the desired information. The collected information was summarized by using the descriptive statistics such as frequency, percentage and mean scoring of the questionnaire. The data management and analysis was done by using Microsoft excel and SPSS.

\section{Results}

The research was conducted on total 20 post stroke patients, of which 13 were males and 7 were females and majority belonged to age group of above 50 years. The distribution of which is, $35 \%$ belonging to age between 50 59 years, $25 \%$ each in 60-69 years and above 70 years of age. Only $15 \%$ belonged to age group of $40-49$ years.

Table 1 shows that when assessed the physical factor of stroke patients, the study showed about $95 \%$ of the patients said their physical functioning had limited a lot post stroke, whereas $5 \%$ said that it was limited a little. The assessment of role physical and role emotional in patients after stroke showed that all (100\%) the patients expressing poor performance in these conditions. About $45 \%$ of the patients expressed that their social life was moderately affected, $25 \%$ said it did a little more than that, whereas $15 \%$ said that it did affect them extremely and other 155 said it only affected their life slightly. About (60\%) of the patients said that they expressed extreme degree of bodily pain. About $25 \%$ said the bodily pain was quite a bit. Next $15 \%$ expressed moderate degree of bodily pain. Majority of patients (55\%) showed fairly good presence of mental 
health, $30 \%$ had a better than the rest. But $15 \%$ were found to have a poor mental health. Assessment of vitality in post stroke patients, majority (60\%) showed good, $25 \%$ were found with fairer degree and remaining 15\% had poor degree of vitality.

Table 1 : Distribution of SF-36 scoring using Likert's scale $\quad N=20$

\begin{tabular}{|c|c|c|c|c|c|c|c|c|c|c|c|}
\hline General health & $\%$ & Physical factor & $\%$ & Social factor & $\%$ & Bodily pain & $\%$ & Mental health & $\%$ & Vitality & $\%$ \\
\hline Excellent & Nil & Not limited & Nil & Not at all & Nil & Not at all & Nil & Excellent & Nil & Good & $60 \%$ \\
\hline Very good & $5 \%$ & Limited a little & $5 \%$ & Slightly & $15 \%$ & A little bit & Nil & Very good & Nil & Fair & $25 \%$ \\
\hline Good & $15 \%$ & Limited a lot & $95 \%$ & Moderately & $45 \%$ & Moderately & $15 \%$ & Good & $30 \%$ & Poor & $15 \%$ \\
\hline Fair & $20 \%$ & ---- & -- & Quite a bit & $25 \%$ & Quite a bit & $25 \%$ & Fair & $55 \%$ & -- & -- \\
\hline Poor & $60 \%$ & ---- & -- & Extremely & $15 \%$ & Extremely & $60 \%$ & Poor & $15 \%$ & -- & -- \\
\hline Total & $100 \%$ & Total & $100 \%$ & Total & $100 \%$ & Total & $100 \%$ & Total & $100 \%$ & Total & $100 \%$ \\
\hline
\end{tabular}

Table 2 showed that the patients did not differ much on the account of various factors like general health, role emotional, mental health or vitality. There is a notable deterioration in social factor in patients above 50 years of age. The vitality, bodily pain, mental health factors were found to decrease as the age advances, without much difference. Physical functioning was less in patients of younger age (40-49 years) than in people of higher age (above 70 years).

Table 2 : Showing the Mean score using SF 36 with respect to age of the patient $\quad N=20$

\begin{tabular}{|l|c|c|c|c|c|c|c|c|}
\hline Age (years) & $\begin{array}{c}\text { General } \\
\text { health }\end{array}$ & $\begin{array}{c}\text { Physical } \\
\text { functioning }\end{array}$ & $\begin{array}{c}\text { Role } \\
\text { physical }\end{array}$ & $\begin{array}{c}\text { Role } \\
\text { emotional }\end{array}$ & $\begin{array}{c}\text { Social } \\
\text { factor }\end{array}$ & $\begin{array}{c}\text { Bodily } \\
\text { pain }\end{array}$ & $\begin{array}{c}\text { Mental } \\
\text { health }\end{array}$ & Vitality \\
\hline $40-49$ & 3.33 & 11 & 4 & 4 & 6 & 3.67 & 22.33 & 9.33 \\
\hline $50-59$ & 2.57 & 11.71 & 4 & 4 & 1.28 & 3.14 & 24.57 & 8.71 \\
\hline $60-69$ & 4 & 12.6 & 4 & 4 & 1.6 & 4.2 & 20.8 & 8.4 \\
\hline 70 and above & 3.6 & 12.4 & 4 & 4 & 1.4 & 3.4 & 22.2 & 8 \\
\hline
\end{tabular}

Table 3 showed that factors like general health and physical functioning is very low in female patients in comparison with male patients. Role emotional, role physical, social factor, and bodily pain are to an extent similar in both the sexes. Mental health and vitality also do not differ much between the two genders.

Table 3 : Showing the Mean score using SF 36 with respect to the sex of the patient $\quad N=20$

\begin{tabular}{|l|c|c|c|c|c|c|c|c|}
\hline Sex & $\begin{array}{c}\text { General } \\
\text { health }\end{array}$ & $\begin{array}{c}\text { Physical } \\
\text { functioning }\end{array}$ & $\begin{array}{c}\text { Role } \\
\text { physical }\end{array}$ & $\begin{array}{c}\text { Role } \\
\text { emotional }\end{array}$ & $\begin{array}{c}\text { Social } \\
\text { factor }\end{array}$ & $\begin{array}{c}\text { Bodily } \\
\text { pain }\end{array}$ & $\begin{array}{c}\text { Mental } \\
\text { health }\end{array}$ & Vitality \\
\hline Female & 2.85 & 2.85 & 4 & 4 & 6.43 & 3.43 & 22.43 & 9.43 \\
\hline Male & 7.08 & 11.54 & 4 & 4 & 6.38 & 4 & 22.84 & 8.08 \\
\hline
\end{tabular}

\section{Discussion}

This study was conducted in 2 months and the quality of life in different domains and health status was measured using Indian version of the Medical Outcomes Study 36 item Short-Form Health Survey (SF-36). Physical functioning and bodily pain was very similar to majority of the patients like earlier studies. Role physical by SF 36 also scored poor. It is also important to note that majority of our patients were daily wagers so may be their physical regain was much earlier. Interestingly our study showed that mental health was fairly good in majority of patient (55\%) which goes against the earlier study where depression, anxiety and mood shift was major problem post stroke ${ }^{(9,10,11)}$. Except one of the study others were done in settings other than India, so the family care giver may be a problem, or problem in care giving as a whole would be a issue for which the mental health would have deteriorated, whereas most of our patients have family care giver and they can get back to the home where they live with family, so anxiety and depression could be less in our patients. It should be also considered that Role emotional was scored poor among the participants.

The social factor was affected quite a bit to moderate. In 
earlier study ${ }^{(12)}$ we could see that they had poor social factor. Social factor in SF 36 is with friends and relatives which is fairly good as in our settings, major area being semi urban joint family concept and relatives are being part of life and acceptance of every member being mandatory would be the reasons. We could see that majority of patients were from higher age group above 50 years and predominantly males being most affected group as shown in all previous studies ${ }^{(1-15)}$. A study ${ }^{(13)}$ stated that, females were more affected and emotionally distressed after stroke where we contradict to say that women cope better than male in all domains except for psychological domain where they scored low. Studies ${ }^{(11,16)}$ showed that as age increases, all the domain score decreases. But in psychological domain we could see that patients with age less than 50 had poor scores as compared to 50-59 years, may be the productive part of life being affected has also affected their mental status. We could see that as socio-economic status decreased domain scores also decreased, except for environmental domain were class IV had fair score compared to class II and III which we explained earlier saying lower expectation in living conditions in poor people.

When we compared patients with different habits we could

\section{References}

1. Mayo NE, Wood-Dauphinee $S$, et al. Disablement following stroke. Disabil Rehabil 1999;21:258-68.

2. Victor M, Ropper AH, Adams RD: Adams \& Victor's principles of neurology. New York, McGraw-hill, 2000.

3. Lo EH, Dalkara T, Moskowitz MA: mechanisms, challenges and opportunities in stroke. Nat Rev Neurosci 4:399, 2003.

4. Dalal.P.M. Burden of stroke- Indian perspective. J Assoc Physicians india 2004;52:695-696

5. Roberts L, Counsell C. Assessment of clinical outcomes in acute stroke trials. Stroke 1998; 29:986-91.

6. Bowling A. Measuring Disease: A Review of Disease-Specific Quality of Life Measurement Scales. Buckingham: Open University Press; 1995.

7. Astrom M, Asplund K, Astrom T. Psychosocial function and life satisfaction after stroke. Stroke 1992;23:527-31.

8. Józef A. Opara, Krystyna Jaracz. Quality of life of post-stroke patients and their caregivers. Journal of Medicine and Life ;2010 (3) (3): pp. 216-220

9. Raju RS, Sarma PS, Pandian JD. Psychosocial problems, quality of life, and functional independence among Indian stroke survivors.Stroke. see that alcohol and smoking contributed to poorer domain scores probably having a bad functional disability with habits as compared to people without habits which is seen in earlier study as well ${ }^{(11)}$. One interesting finding is that with all the difference our patients scored good vitality scores by SF 36 which is not similar to earlier studies ${ }^{(11,14,15)}$.

\section{Limitations}

This was a study for 2 months and our college hospital being one of the 21 tertiary care hospitals catering for 12 lakh population gets only few patients for which sample size is very limited.

\section{Conclusion}

The study reported varied results but environmental domain being fairly good, social factor good but other domain to be poor. Though psychological domain and role emotional was poor, mental health was fair to good. Physical domain showed fair but physical factor and bodily pain was seen to be a lot.

\section{Acknowledgement}

A sincere thanks to all the patients who gave their consent for participation in the study. We also thank staff from Departmet of Neurology who gave permission to conduct this study on their patients.

2010 Dec;41(12):2932-7. Epub 2010 Oct 21.

10. Haley WE, Roth DL, Kissela B, Perkins M, Howard G. Quality of life after stroke: a prospective longitudinal study.Qual Life Res. 2011 Aug;20(6):799-806. Epub 2010 Dec 7Sturm JW, Donnan GA, Dewey $\mathrm{HM}$, et al. Quality of life after stroke:The North East Melbourne Stroke Incidence Study(NEMESIS). Stroke 2004:2340-234

11. Rouillard S, De Weerdt W, De Wit L, Jelsma J. Functioning at 6 months post stroke following discharge from inpatient rehabilitation.S Afr Med J. 2012 May 23;102(6):545-8.

12. Gall SL, Donnan G, Dewey HM, Macdonell R, et al. Sex differences in presentation, severity, and management of stroke in a populationbased study.Neurology. 2010 Mar 23;74(12):975-81. Epub 2010 Feb 24.

13. Dayapoglu N, Tan M. Quality of life in stroke patients. Neurol India. 2010 Sep-Oct;58(5):697-701.

14. Opara JA, Jaracz K.J Med Life. Quality of life of post-stroke patients and their caregivers.2010 Jul-Sep;3(3):216-20.

15. Jucha R. Functional status and quality of life of stroke survivors living in rural areas and small towns. PrzegILek. 2012;69(3):98-102. 